\title{
Introduction: Sustaining Growth and Ending Poverty in Asia
}

\author{
Mark Robinson and John Farrington ${ }^{1}$
}

\begin{abstract}
1 Overview
Asia has witnessed an unprecedented period of growth and poverty reduction over the past decade. Sustained growth has contributed to a dramatic reduction in poverty and vastly improved standards of living in most Asian countries. The majority of countries are making steady progress towards the achievement of the Millennium Development Goals (MDGs) as a result of economic growth and increased public investment in health and education services. People are living longer, literacy rates are improving and infant and maternal mortality rates are falling.

However, while the prospects for sustained development are promising continued growth and poverty reduction over the coming decade are by no means assured. Economic growth at current levels could halve poverty by 2015. But growth alone cannot eliminate poverty in the region. Inequality is likely to increase without concerted public action to ensure that the poor benefit from growth and to protect and support vulnerable groups. In the absence of such intervention, substantial numbers of people would remain economically marginalised and socially excluded, especially in South Asia and other lagging regions.
\end{abstract}

Asian countries also face a number of challenges: the potential for renewed financial instability; rising inequality of incomes and wealth; inadequate levels of infrastructure and energy supplies; and the threat of environmental degradation. Conflict between states, rising terrorist activity and political instability are all plausible political risks. There is also the prospect of threats that lie outside the immediate control of governments - disease pandemics, natural disasters, a global economic downturn, and largescale armed conflict on a world scale - which could significantly undermine continued progress in Asia.
While Asia as a whole faces a number of common challenges, it is important to emphasise that the region is very heterogeneous. It includes emerging global players like China and India as well as a number of smaller states. From Central Asia to the Pacific Rim, and from Mongolia to Indonesia, there are major differences in ethnicity, creed, integration in world markets, and topographical, climatic and agro-ecological conditions. There is also considerable variation in regime type and political context. Asian countries also differ in terms of their performance, the specific threats they face, the policy choices they confront, and new and changing partnerships. ${ }^{2}$ Moreover, there are significant differences in patterns of development, levels of wealth, the nature of poverty and inequality, the depth and extent of social exclusion, and forms of governance.

There are also important variations within countries in the region. While China and India are experiencing high rates of growth there are lagging regions in both countries, especially in more remote areas that are poorly served by infrastructure and services, characterised by a slower pace of development and higher concentrations of poverty and exclusion. Progress on the MDGs also varies considerably across subregions, correlated to some degree with poverty levels, but also reflecting social and cultural factors.

\footnotetext{
The implications of high levels of Asian growth for other parts of the developing world are the subject of a previous issue of the IDS Bulletin, which focused on the so-called Asian drivers of change, especially the global economic and political significance of the two emerging regional economic giants, China and India. ${ }^{3}$ In this issue, the emphasis is on the implications of rapid development within the region, focusing on the challenges and opportunities posed by high levels of growth. This was the focus of a high level
} 
conference in March 2006, which sought to highlight the remarkable achievements of the region and the prospects for sustaining current rates of progress over the decade leading up to $2015 .{ }^{4}$ The implications for future partnerships between Asian countries and between Asia and the rest of the world, especially for aid, trade, investment and global public goods, were a focal point for the conference. The ten articles in this IDS Bulletin draw on thematic papers prepared for the conference on the twin themes of growth and poverty reduction. A brief review of the main features of Asia's development experience serves to locate these articles in a broader context.

\section{Growth and poverty reduction}

Sustained growth in Asia has been accompanied by a process of structural transformation, with agriculture accounting for a declining share of gross domestic product (GDP) as the manufacturing and service sectors have expanded. Growth is associated with a rapid process of urbanisation and the development of dynamic regions, especially in the coastal areas across many countries. Urban areas are now the principal motors of growth in the region, though two-thirds of the population in the most populous countries - Bangladesh, China, India, Indonesia and Pakistan - continue to derive their livelihoods mainly from agriculture.

Asian experience points to a clear relationship between growth and poverty reduction. High growth rates have been associated with steep and progressive declines in poverty incidence. According to World Bank data, poverty rates in Asia as a whole almost halved in the last decade, with the headcount ratio (based on a consumption level of less than $\$ 1$ per day) falling from 34.3 per cent in 1990 to 19.3 per cent in 2003. Countries such as China, Indonesia, Malaysia, Thailand, Vietnam and Sri Lanka all reduced poverty by half during this period, and are on track to meet targets corresponding with the MDG of a further 50 per cent reduction in income poverty by 2015. Despite this impressive progress, two-thirds of the world's poor live in Asia, with limited livelihood opportunities and poor access to basic services.

The expectation is that if growth continues at current levels to 2015 the headcount ratio would decline to between 2.9 and 6.7 per cent depending on trends in income inequality. For South Asia, the figure is likely to remain in the region of 12.8 per cent, well under half the present level. The most optimistic projections expect income poverty in Asia to be eradicated completely by 2025 (i.e. in less than a generation) if current growth trends persist. Even if many countries are capable of reducing absolute poverty to minimal levels, the region as a whole will continue to have over a billion people living below a relative poverty line of $\$ 2$ per day in $2015 .{ }^{5}$

There is also considerable variation in rates of poverty reduction within and across countries and over time. Significant progress for the poorest social groups is by no means assured. Much depends on how the costs and benefits of growth are distributed and how far the growth process creates opportunities for poor people to participate in economic activity. Achieving pro-poor growth requires policy attention to the manner in which the poor gain access to formal sector employment and acquire productive assets and to the distributional consequences of different growth trajectories.

However, growth alone cannot eradicate poverty without commensurate public action to tackle problems of exclusion, marginalisation and the threat of rising inequality. Marginalised social groups do not always benefit directly from economic growth, especially those living in lagging regions which are either geographically remote or located in difficult agro-climatic areas. Spatial inequality and regional concentration of poverty are of concern because they limit the market for local goods and services and can undermine social and political cohesion. Addressing such problems will require a combination of fiscal measures and resource transfers to ensure that the benefits of growth are more widely shared, with increased attention to the role played by local governments in service provision and economic development, especially in decentralised systems.

Addressing the problems faced by poor people in lagging regions requires direct public interventions in the form of investment in rural roads, schools and health centres, improved productivity in the agricultural sector, the creation of non-farm employment opportunities, and improved health and education services. Migration to richer areas offers an important route out of poverty for the rural poor and can contribute to economic growth, and lagging regions can benefit from remittance income. But the problem of urban poverty is also increasing as urbanisation proceeds apace and cities attract migrants in search of better job prospects. The urban 
poor not only face problems of economic deprivation but also poor housing, inadequate amenities and pervasive criminality. A range of complementary measures is required to address urban poverty, including access to residential land, housing and infrastructure, adequate provision of social services, and employment and income generation. ${ }^{6}$

The urban and rural poor in Asia also encounter discrimination stemming from ethnicity, race, religion, caste, gender and place of origin. Poverty is especially concentrated among low castes in India, racial minorities in China, and religious minorities in Bangladesh and Pakistan. Women are an especially vulnerable group in all these categories. Social protection measures are required to address identitybased forms of discrimination and economic deprivation commonly faced by these groups.

The poor in Asia face considerable problems in accessing affordable and quality public services. Public provision remains uneven and resource outlays are very low in some countries. The private sector and non-governmental organisations (NGOs) play a key role in health and education provision in some countries, but these often supplement the public system and rarely reach the poor on a large scale. Various countries in the region are experimenting with decentralisation and public-private partnerships as a means of improving access for the poor and investing increasing resources in the public system in pursuit of the health and education MDGs.

Governance practices vary considerably across countries in the region. While no single model of governance is associated with positive growth and poverty reduction outcomes the most successful countries are characterised by effective states that have provided a supportive policy framework for rapid growth. The least developed countries face problems of political instability, weak territorial control and endemic corruption. There is growing recognition among policy makers in the region that successful resolution of governance challenges is critical to the successful pursuit of continued growth and poverty reduction, hinging on incremental reform and construction of effective and accountable states rather than on rapid progress towards democracy.

\section{Key themes}

This issue of the IDS Bulletin brings together ten articles that examine the challenges of sustaining current growth trends and the structural features of poverty and exclusion outlined in the previous section. As noted earlier, sustained growth is not assured and there are threats that could throw further progress off-track and potentially erode the tremendous gains achieved to date. Articles in this IDS Bulletin examine these threats and suggest ways in which potential challenges might best be mitigated through conscious policy choice and public action under the leadership of Asian governments.

Bass and Steele examine the main environmental challenges posed by rapid and resource-intensive economic growth - deforestation, pollution, and pressure on water supplies - arguing that failure to address these growing problems will pose real limits on future growth. They also propose the adoption of a 'green growth' strategy that enables the poor to gain from growth derived from natural resource endowments.

Griffith-Jones and Gottschalk highlight the risks posed by financial vulnerability, showing how financial crisis or economic slowdown can undermine efforts to reduce poverty. They examine the strengths and weaknesses of Asian economies, in terms of the strength of financial markets and the banking system, financial regulations, and measures to promote financial stability and crisis prevention among governments in the region.

The private sector is a major driver of economic growth in Asia and the investment climate comprising infrastructure and the regulatory environment - is a key determinant of the willingness of the private sector to invest in the region. In her contribution Phillips examines the constraints on investment, demonstrating how small and medium enterprises suffer disproportionately from weaknesses in the regulatory environment, especially in the rural sector, but that large firms are affected by infrastructure bottlenecks and poorly functioning customs and tariffs regimes. In order to address constraints on investment, Phillips argues for a complementary set of measures centred on regulatory reforms and mechanisms to enhance reputation and reduce risk in collaboration with the business community.

Jones explores the importance of infrastructure as a key determinant of economic growth and poverty reduction, demonstrating how current levels of 
investment fall well below those required for sustaining growth. He argues that public and private investment are both required to stimulate growth and reduce poverty, and that investment in rural roads, education and agricultural research is the surest route to promoting pro-poor growth.

A further set of articles consider the implications of high growth rates for poverty reduction and social exclusion, and changing patterns of urbanisation and migration in the region.

Demonstrating how gender and spatial dimensions of poverty overlap with and reinforce economic deprivation and identity-based discrimination, Kabeer examines how social exclusion makes it difficult for certain categories of poor people to take advantage of the opportunities generated by economic growth. She argues that a multi-pronged approach founded on social protection is required to address problems of exclusion and poverty, entailing a combination of legal provisions, educational initiatives to tackle entrenched cultural norms and promote attitudinal change, and the mobilisation of socially excluded groups through civil society networks.

Jack's contribution examines the complex and contradictory nature of urbanisation in Asia, showing how it both contributes to economic growth and at the same time creates major challenges in relation to land use, shelter, infrastructure and the provision of basic services. He outlines how initiatives under way in the region can contribute to effective solutions to the challenges posed by rapid urban development centred on integrated approaches to planning and innovation

Hussain, Cassen and Dyson highlight the significance of sharp reductions in life expectancy and infant mortality and sharp declines in the total fertility rate, all of which are leading to falling population growth rates across the region but with high rates of growth persisting in South Asia. Their article explores the significance of demographic trends in Asia and their consequences for education provision, social security and the environment.

High rates of internal migration within Asian countries are the focus of Deshingkar's contribution. Observing how migration has enormous potential for reducing poverty and stimulating economic growth through employment generation and remittances, Deshingkar highlights how government policies have tended to discourage migration and stigmatise migrants to the detriment of growth and poverty reduction in lagging regions and host areas.

Two further articles by Joshi and by Rahman and Robinson respectively consider how governments in the region are responding to the challenge of improving the quality and accessibility of public services, and addressing the problems of poor governance that threaten to undermine growth and prosperity if left unchecked. Joshi draws attention to problems of access, quality and affordability and sustainability that inhibit effective service delivery to the poor, arguing that a wider plurality of providers, improved regulation and better articulation of voice by clients can all serve to produce improvements. As emphasised by Rahman and Robinson in their contribution, government agencies are central to creating a favourable environment for growth and poverty reduction through supportive policies and public investment, and state effectiveness is key to developmental success. They argue that governance will remain central in the next phase of Asia's growth through the creation of effective and accountable states. Improved governance is also integral to future poverty reduction efforts, centred on decentralisation and service delivery reforms along the lines being pursued by several governments in the region.

Three common threads underpin the articles in this volume. First, the recognition that the solutions and policies for mitigating risk and building on opportunities emanate primarily from actors within the region. Second, national governments are the key actors in developing innovative ideas, formulating policies, and raising and deploying resources. Third, while governments play a central role in creating a favourable policy environment, there is potential for developing more enduring partnerships in the pursuit of the twin objectives of sustaining growth and ending poverty. The private sector has been the major engine of growth through innovation, investment and employment creation. NGOs also play an important role - by articulating the voice of the poor and marginalised, protecting the rights of the socially excluded, and mobilising additional resources for development. Donors and multilateral financial institutions have been an important source of finance in the past though development assistance now plays an increasingly marginal role in the larger Asian countries. The declining financial significance of 
aid at a time of rapid growth and expanding trade and investment flows point to the likelihood of very different partnerships between Asian countries and international aid agencies in the future.?

New forms of partnerships are likely to be central to future poverty reduction efforts in the region. The

\section{Notes}

1 Further Asia 2015 conference papers are published in a companion issue of Development Policy Review, Volume 24, Supplement 1, August 2006.

2 We are grateful to Lawrence Haddad for highlighting this point. The ideas in this paragraph derive largely from his contribution to the Asia 2015 Conference Discussion Forum.

3 'Asian Drivers: Opportunities and Threats', IDS Bulletin 37.1, January.

4 Asia 2015: Promoting Growth, Ending Poverty, 6-7 March 2006. The conference was co-hosted by the UK Department for International Development, the Asian Development Bank, and the World Bank. The Institute of Development Studies and the Overseas Development Institute articles in this issue of the IDS Bulletin and in the companion issue of Development Policy Review highlight a range of ways that intensified cooperation between governments, the private sector and non-governmental actors, with selective support from external actors, can help to sustain further progress in the coming decade.

jointly produced most of the background papers for the conference, many of which form the basis for the papers in this issue of the IDS Bulletin and the Development Policy Review. For details see www.asia2015conference.org

5 Humphrey, J., 2006, 'Prospects and challenges for growth and poverty reduction in Asia', Development Policy Review 24: Supplement 1.

6 Cook, S., 2006, 'Structural change, growth and proverty reduction in Asia: Pathways to inclusive development', Development Policy Review 24: Supplement 1.

7 Partnerships were an important theme in the Asia 2015 conference, and are the focus of an article by Simon Maxwell and Mark Robinson in the companion volume of Development Policy Review. 


\section{Asia 2015: Promoting Growth, Ending Poverty}

Asia 2015 was a major two-day conference held in London on 6-7 March 2006, hosted by the Department for International Development (DFID) and co-sponsored by the World Bank and Asian Development Bank. Around 150 delegates, mainly from Asia, attended this unique gathering of senior politicians and government officials, and representatives from the private sector, civil society and international development agencies.

The conference provided a platform to discuss the changing face of development in Asia over the next decade and the implications for how DFID and the international community should respond. $A$ number of themes were discussed through a series of panel-led debates, looking both at the challenges facing Asia now and at how to maintain and bring about success in the future.

The main themes of the conference are presented in this issue of the IDS Bulletin, which draws together several of the background papers written for the panel discussions. $A$ further set of papers will appear in the August 2006 special issue of Development Policy Review. One theme was how to promote action to ensure sustainable growth. There are many potential constraints including environmental degradation, energy and resource shortages, and inadequate investment in infrastructure and skills.

A second major theme for discussion was the ways to unleash the potential for poverty reduction by ensuring that growth creates opportunities for poor people and that human development needs are met. Asian countries need support as they cope with uneven development and rapid urbanisation that is giving rise to new forms of poverty.

The third theme focused on sharing the lessons of development. Asia experience leads the world and this was an opportunity to highlight key aspects of that success that are relevant to other regions.

Finally, the conference focused on the concept of taking forward new forms of mutually beneficial partnership to address the challenges presented by a diverse and modern Asia.

For a full range of background papers and speeches at the conference see www.asia2015conference.org 